\title{
Discurso e(m) folkosonomia: o Brasil vestido com algumas tags
}

\section{Vivian Lemes Moreira e Lucília Maria Sousa Romão}

\section{Resumo}

0 trabalho presente tem como objetivo discutir as formas de organização e indexação dos arquivos digitais inscritas pelo sujeito-navegador na Web. Assim, é estabelecido um delineamento e uma discussão sobre o discurso introduzido pelo sujeito na Internet, levando em conta as condições de produção da discursividade eletrônica. Mobilizando os conceitos sobre Internet e folksonomia, pretendemos construir um diálogo com a Análise do Discurso de matriz francesa para investigar o funcionamento discursivo das tags, palavras que indexam, de forma considerada livre, os arquivos na rede eletrônica. Com isso, observaremos a forma como a tag "Brasil" tem sido utilizada pelos sujeitos-navegadores para nomear e indexar arquivos do website Flickr. Para este percurso serão analisadas as marcas linguísticas deixadas pelos sujeitos-navegadores nas tags, essas que fazem falar (e calar) certas palavras, investigando assim o modo como os dizeres são instalados através do processo da folksonomia.

\section{Palavra-Chave}

Discurso. Sujeito. Folksonomia. Brasil. Rede Eletrônica.

\section{Vivian Lemes Moreira I viviannlk@gmail.com}

Bacharel em Ciências da Informação e Documentação pela USP. Mestranda em Psicologia pela Faculdade de Filosofia Ciências e Letras de Ribeirão Preto/Universidade de São Paulo - USP.

\section{Lucília Maria Sousa Romão | lucilamsr@ffclrp.usp}

Doutora em Psicologia pela Universidade de São Paulo - USP. Professora da Faculdade de Filosofia Ciências e Letras de Ribeirão Preto/USP. Tem experiência na área de Lingüística, com ênfase em Teoria e Análise Lingüistica.

\section{Um percurso e $(m)$ redes de dizer e organizar os ditos}

fora das palavras, não há nada José Sarmago

Em trabalhos anteriores (MOREIRA; ROMÃO, 2009; MOREIRA; SILVA; ROMÃO, 2010), discutimos questões pertinentes aos movimentos do sujeito no espaço eletrônico, especialmente relacionando discurso, memória e folksonomia. Nesse trabalho, objetivamos refletir sobre os discursos que circulam na rede através da tag "Brasil" inserida pelos sujeitos-navegadores no website Flickr, discutindo como essa forma de organização trazida pela folksonomia temse refletido na organização das informações e nas buscas realizadas por meio das tags que indexam conteúdos na malha digital. Procuramos, também, observar como essas etiquetas são afetadas pelas condições de produção do discurso, considerando que elas nos convidam a analisar também o modo como são realizadas as práticas de categorização no âmbito da Ciência da Informação, especialmente, na organização de websites. Ao trabalharmos com os recortes 
selecionados, buscaremos flagrar a forma como os sujeitos produzem (seus) sentidos nomeando dados e arquivos, e criam, dessa maneira, espaços discursivos de dizer e de calar; ou seja, estamos sustentando que dar um nome a uma tag tem uma implicação maior do que apenas "escolher" uma palavra, visto que instala um lugar no discurso entendido aqui conforme Pêcheux (1983). Um aspecto importante que está no horizonte desse trabalho é o diálogo entre as áreas da Ciência da Informação/ Biblioteconomia, Análise do Discurso e Sociologia da Informação (rede eletrônica), visando a uma reflexão sobre as possibilidades de interpretação da organização das informações na Web introduzidas pelo sujeitonavegador. Enfatizamos que as análises, sob a ótica da Análise do Discurso, leva-nos a olhar de outro modo tanto para a informação quanto para a forma como ela é organizada e recuperada pelos sujeitos-navegadores, posto que as palavras estão sempre em movimento e em desdobramento, fadadas a serem (re)significadas a todo momento.

\section{Web e folksonomia: os movimentos de sentidos em tags}

Não sou eu quem joga com as palavras, são elas que jogam comigo.

José Saramago

0 século XIX foi marcado pelo surgimento de inovações tecnológicas que facilitaram a comunicação entre os seres humanos, permitiram a transmissão de informações a grandes distâncias. Com o aumento da tecnologia a serviço da comunicação, o fácil acesso da sociedade a grandes quantidades de informação foi crescendo de forma vertiginosa, e grande parte desse fácil acesso às informações podese dizer que foi ocasionada pela Internet. Segundo Wurman (1991, p. 312): “A explosão da informação não ocorreu apenas devido a um volume maior de informação. Avanços na tecnologia de transmissão e de armazenamento também influem. Somos afetados tanto pelo fluxo quanto pela produção de informação". A Internet é 0 aparato das Tecnologias da Informação e Comunicação (TIC's) que obteve uma grande influência em relação ao fluxo e à produção de informações, e também em relação aos espaços possíveis para o sujeito dizer de si e discursivizar o outro e os objetos. Ela pode ser definida como:

[...] um conjunto de inúmeras redes de computadores, conectadas entre si, que permite a comunicação, partilha de informações, programas e equipamentos entre seus usuários. Constitui a infra-estrutura sobre a qual trafegam grande volume de informações e outros serviços (BRANSKY, 2004, p. 71).

A generalização da Internet teve sua "explosão" em crescimento no ano de 1994, com o início do uso comercial em grande escala do protocolo HTTP para a montagem de sites. A partir desse momento, ela começou a crescer e evoluir de forma vertiginosa e hoje em dia ela é vista como o tecido de nossas vidas contemporâneas (CASTELLS, 2001), já que invadiu os locais de trabalho, estudo e pesquisa além de estar cada vez mais presente em setores como a saúde, 
economia, entre outros. Segundo o mesmo autor (2001, p. 7), "uma rede é um conjunto de nós interconectados. A formação de redes é uma prática humana muito antiga, mas as redes ganharam vida nova em nosso tempo transformando-se em redes de informação energizadas pela Internet". Assim, o movimento de dizer em rede e de poder estar em um ponto da rede configura a net como algo em constante criação (imprevisível, para dizer o mínimo), cuja produção, constituição e circulação da linguagem dão-se a (des)conhecer de modo sempre incompleto e em uma página além, mais adiante ou mais atrás, ou seja, algo que está fugidiamente em trânsito. Isso, no contexto da Web 2.0, faz falar dizeres de sujeitos que navegam em uma superfície cujo modo de organização é particular, fractal, espalhado e diferente da linearidade do impresso, modo esse em que a interatividade é 0 imperativo, a palavra está em con-fusão com outras materialidades, a voz do sujeito desfiada pela heterogeneidade e 0 discurso em constante movimento.

0 termo Web 2.0 surgiu em uma conferência "brainstorming session" durante um debate entre Tim 0'Reilly e MediaLive International no ano de 2004, a fim de discutir os novos rumos da Internet após o estouro da bolha pontocom. 0 fenômeno conhecido como estouro da bolha pontocom foi uma onda de falências de empresas virtuais e a consequente desvalorização vertiginosa das ações listadas em bolsa. Houve um grande prejuízo, muitas pessoas perderam dinheiro e chegaram a desacreditar o futuro da Internet. A desvalorização da bolsa seguiu até 2002, mas foi perdendo a força, até que se estabilizou; entretanto, o estouro da bolha causou consequências, as quais geraram a necessidade de serem discutidas, o que possibilitou 0 nascimento de uma segunda geração da Internet, a Web 2.0. A partir daí, estudiosos de todo o mundo começaram a refletir sobre esse novo termo, que não é denominado como uma tecnologia, mas sim um termo designado a um conjunto de conceitos que mudou a forma de pensar e construir a Internet. Considera-se relevante marcar aqui que, com o início da Web 2.0, houve a construção de um espaço materializado, conduzido e remexido pela voz do sujeito-navegador com as diversas páginas e arquivos que ele pode criar e compartilhar, (des)construindo e (des)fazendo dizeres e imagens que, por sua vez, são linkados e presos por fios, pontos de encontro e nós. Chartier (2002, p. 25) afirma que

0 texto eletrônico, tal qual o conhecemos, é um texto móvel, maleável, aberto. 0 leitor pode intervir em seu próprio conteúdo e não somente nos espaços deixados em branco pela composição tipográfica. Pode deslocar, recortar, estender, recompor as unidades textuais das quais se apodera. Nesse processo, desaparece a atribuição dos textos ao nome de seu autor, já que estão constantemente modificados por uma escritura coletiva, múltipla, polifônica.

A Web 2.0 promoveu essa interação do sujeitonavegador com os arquivos digitalizados que potencializou a publicação e a circulação de 
informações e que ainda promoveu uma nova forma de organizar as informações na rede, por meio da folksonomia. Ela pode ser considerada a prática de classificação/ categorização/ indexação colaborativa de conteúdos na malha digital, realizada pelo próprio sujeito-navegador, a partir de sua navegação. No processo da folksonomia, o sujeito-navegador rotula, nomeia, designa suas palavras, dados e arquivos de forma livre, não existindo nenhuma metodologia e/ou etapas a serem realizadas para a organização e a recuperação das informações de seu interesse. Para Catarino e Baptista (2007, p. 11), "a folksonomia é uma taxonomia dinâmica que representa as categorias que os usuários individuais empregam para organizar suas informações em um determinado espaço". Tal processo envolve, segundo Hsieh, Yen-Lin e SengChou (2009, p. 951), três elementos básicos: a) o sujeito que está criando as tags; b) o objeto que está sendo nomeado por meio dessa tag; e c) as tags que estão sendo aplicadas aos objetos

Desta forma, por meio desses três elementos básicos, a folksonomia permite que as informações sejam organizadas de forma simples e flexível feita por qualquer pessoa que se habilite a criar uma tag (etiquetas/rótulos de identificação) para organizar conteúdos de seu interesse na rede.

Pensando do ponto de vista discursivo, as tags são nomeações que abarcam os sentidos disponíveis ao sujeito na posição que ocupa, ou seja, implicam a formação discursiva à qual ele está filiado e também a memória discursiva à qual ele retornou para poder designar. Dessa forma, existem tags (e em um discurso utilitarista, servem) somente para o próprio sujeito criador da tag localizar seus links e documentos na rede; sem dúvida, isso problematiza e complexifica 0 trabalho de recuperação da informação para os outros navegadores do sistema. Não sem razão, esses tipos de tags são chamados por Kipp (2007) de "affective tag", ou seja, tags de cunho afetivo, tais como: legal, interessante, bonito; que possuem o conteúdo muitas vezes recuperado somente pelo seu criador.

Alguns pesquisadores têm se debruçado sobre as formas de apresentação da folksonomia; para Lipczak (2008), a folksonomia pode ser apresentada por duas formas: a individual e a coletiva. 0 primeiro tipo pode ser representado pelo sistema de bookmarking Delicious, no qual as tags são criadas para orientar 0 sujeitonavegador a encontrar seus próprios documentos; dessa maneira, podem existir muitas "affective tags" visto que, segundo Lipczak (2008, p. 2), "this type is referred to as folksonomies oriented towards individual users"1. 0 segundo tipo de folksonomia pode ser representado pelas tags encontradas em blogs, tais como do sistema de blog Technorati, que consiste em um repositório de compartilhamento de informações 
e documentos, na qual as tags após de criadas são utilizadas para recuperar informações e ou documentos através dos campos de busca, tendo como característica o compartilhamento das informações entre os leitores na Web. Para Lipczak (2008, p. 2), "this type is referred to as folksonomies oriented towards broad audience"2. Discutiremos a seguir como a folksonomia apresenta-se no sistema Flickr, a partir da tag "Brasil"; iremos percorrer quais sentidos heterogêneos e imprevisíveis os sujeitosnavegadores têm atribuído à referida tag e como se dá a (des)organização no âmbito individual e coletivo no referido website. Para tal, falemos de discurso, heterogeneidade e memória discursiva.

\section{Outro(s) navegante(s) na voz dos sujeitos: heterogeneidade e discurso}

A representação mais exacta, mais precisa, da alma humana é o labirinto.

Com ela tudo é possível.

José Saramago

A partir de agora, faremos um passeio pela teoria da Análise do discurso de filiação francesa, mobilizando as noções de discurso, heterogeneidade (AUTHIER-REVUZ, 2004) e memória discursiva (PÊCHEUX, 1999) para analisar as interações dos sujeitos e dos sentidos nas tramas discursivas na Web, em particular no que tange à organização dos arquivos inscritos pelos navegadores no website Flickr. Para a AD, a noção de discurso está relacionada à língua e aos efeitos de sentidos entre os interlocutores do discurso, o que implica compreender as posições de onde os sujeitos enunciam e o fluxo das palavras no movimento das relaç̧ões de poder (PÊCHEUX, 1983).

Pontuamos, então, que o discurso é muito mais que uma junção de palavras de acordo com regras gramaticais, 0 que atribui uma suposta noção de homogeneidade e linearidade ao discurso; ele é, pois, um jogo de efeitos de sentidos entre interlocutores no âmbito de formações discursivas datadas historicamente. Introduziremos aqui a noção de formação discursiva (FD), identificada por Pêcheux como um processo no qual "o sujeito do discurso continua sendo concebido como puro efeito de assujeitamento à maquinaria da FD com a qual ele se identifica" (PÊCHEUX, 1983, p. 314). Denominamos que ela é configurada pela projeção, na linguagem, das formações ideológicas que determinam 0 que pode e 0 que deve ser discursivizado dentro de uma formação social; e é preciso considerar que tal processo é movediço e mutante, como os sentidos das palavras.

Assim, tocar o conceito de formação discursiva remete-nos à noção de memória discursiva, já que há sempre um dizer anterior que sustenta a possibilidade de nossa inscrição na linguagem. Entendemos que, nos enunciados mais simples e até nos mais complexos, os sentidos são 
emprestados (ora para reafirmar, ora para deslocar) de outro(s) discurso(s), posto que as palavras guardam inscrições de seus usos sociais em outros contextos. De acordo com Maingueneau (1993, p. 115), "toda formação discursiva é associada a uma memória discursiva, constituída de formulações que repetem, recusam e transformam outras formulações". Por isso, o discurso configura-se sempre por sobre um já-falado-antes e um já-dito em outro lugar, 0 que nos permite inferir que todo discurso é heterogêneo do ponto de vista discursivo.

Há uma heterogeneidade constitutiva do próprio discurso e que é produzida pela dispersão do sujeito. 0 sujeito, na $A D$, deixa de ser centro e origem do seu discurso para ser entendido como uma construção polifônica, lugar de significação historicamente constituído (NARVAZ; NARDI; MORALES, 2006, p. 5).

0 conceito de heterogeneidade discursiva ajuda-nos a analisar o discurso do navegador na rede eletrônica onde o sujeito está, a todo momento, recortando e colando palavras que não são suas, posto que já ditas por outrem, em outras páginas e tantos outros arquivos; na mesma medida, em que inscreve as "suas" palavras a serem remexidas e recortadas por outros. 0 conceito de heterogeneidade discursiva desconstrói a máxima de que o discurso é sempre homogêneo e unívoco, possibilitando-nos escutar os efeitos de contradição, deslocamento, ambiguidade e desarranjo de outro modo, não como erros a serem reparados, mas como condição de todo discurso, sempre atravessado e saturado por outros tantos discursos.
0 termo heterogeneidade discursiva é utilizado pela AD (PÊCHEUX, 1983) para destacar que todo discurso é atravessado pelo discurso do outro, ou por outros discursos. A AD rompe, dessa forma, com as tentativas de homogeneidade e de ilusão de identidade tanto do sujeito, quanto dos discursos, sendo marcada, em especial na atualidade, pela plurivocidade e pela heterogeneidade discursiva, explodindo com os discursos monológicos, unívocos e homogeneizantes (PÊCHEUX, 1983) (NARVAZ; NARDI; MORALES, 2006, p. 5).

De acordo com Authier-Revuz (2004), existem duas formas de heterogeneidade: a primeira é configurada pela heterogeneidade constitutiva que se caracteriza por meio da presença de outros discursos em um único discurso, de uma forma não explícita, na qual o nome do outro não é revelado, mantendo-se na superfície da memória e do interdiscurso. A memória que referenciamos aqui não se trata da memória saudosista, nem tampouco da memória cronológica, mas sim da memória discursiva abordada no âmbito da $\mathrm{AD}$; ela é aquela que torna possível todo enunciado, é o saber discursivo ao qual o sujeito se entrega para enunciar. Ela sustenta a rede de sentidos já ditos e até mesmo aqueles já esquecidos de dizer, essa rede que determina a emergência dos discursos. A memória discursiva indica a heterogeneidade constitutiva, ligando o já-dito com o que está na base do dizível; e o sujeito, na tentativa de anulála ou driblá-la, procura mostrar a transparência, a univocidade do/ao sentido em seu dizer, afetado pelas duas formas de esquecimentos (PÊCHEUX, 1990). No esquecimento número um, o sujeito 
tem a ilusão de ser 0 autor do discurso no momento da enunciação, como se as palavras surgissem dele no momento em que estão sendo ditas, como uma fonte única do sentido de seu discurso. Já no esquecimento número dois, o sujeito acredita que as palavras possuem o sentido que ele atribuiu, esquecendo-se de outros sentidos possíveis que essas mesmas palavras poderiam estar ali, e mantendo de pé a ilusão de que 0 discurso reflete 0 seu conhecimento objetivo sobre a realidade e assinala uma relação termo a termo com 0 mundo (PÊCHEUX,1983).

A segunda forma da heterogeneidade é denominada pela autora como mostrada porque marca e traduz a presença explícita do Outro no discurso. Segundo Authier-Revuz (2004), ela apresenta-se de duas maneiras, quais sejam, as formas marcadas e não-marcadas da heterogeneidade mostrada; a primeira, da ordem da enunciação, é possível ser visualizada na materialidade linguística, como, por exemplo, citações diretas em um texto, 0 emprego de aspas na escrita; e a forma não-marcada caracteriza-se pelo modo como o sujeito dilui e amarra a sua voz com a do outro em um discurso, como exemplo, podemos citar 0 discurso indireto e a ironia.

As bases teóricas mostradas até aqui sustentam os movimentos do sujeito na Web, esta que se configura como um espaço interativo, heterogêneo, em que 0 sujeito- navegador vai cortando e colando os dizeres como se fossem diversas peças em um grande mosaico, configurado pela rede eletrônica. Ele monta seu dizer e estabelece a todo momento uma relação tensa entre 0 do outro e 0 seu, entre 0 dito e silêncio.

\section{Meu Brasil brasileiro: a circulação de certos efeitos de sentidos}

vou cantar-te nos meus versos

Ary Barroso

Após o trajeto realizado até aqui, foi possível fazer um delineamento sobre as formas de organização e recuperação dos arquivos na rede eletrônica e a interação do sujeito-navegador a partir da Web 2.0, que implicou em novas formas de organização e circulação dos dizeres e arquivos na rede. Sob a ótica da Análise do Discurso de filiação francesa, iniciaremos a análise de um corpus composto por recortes discursivos encontrados no Flickr. Observaremos a forma como o sujeito-navegador tem nomeado, organizado, indexado de forma livre seus arquivos por meio da folksonomia, flagrando, na ordem da língua, os deslizamentos de sentidos instalados na tag "Brasil". Buscaremos entender como a memória discursiva marca presença em várias maneiras por meio de diversas vozes na retomada do interdiscurso sobre a palavra "Brasil" e as decorrências disso na discursividade heterogênea do/no Flickr, com os efeitos de sentido do verbal superpostos nesse mundo-imagem (MOREIRA; 
SILVA; ROMÃo, 2010). Considerando que sentidos e sujeitos movimentam-se ao sabor das redes de memória, intentamos investigar quais sentidos sobre o "Brasil" circulam nesse site, como são produzidos, a que regiões do interdiscurso filiam-se os sujeitos, enfim, de que modo a língua e a história fazem sentido. A referida tag foi selecionada com o intuito de flagrarmos justamente como e em quais arquivos eletrônicos o sujeito tem atribuído sentidos de "Brasil"; assim, rastreamos como o significante Brasil tem sido discursivizado na Web a partir do sistema Flickr.

O Flickr é uma das páginas eletrônicas mais cultuadas da chamada Web 2.0, pertencente ao grupo Yahoo!. 0 Flickr é um aplicativo online de gerenciamento e compartilhamento de fotos e vídeos entre os sujeitos-navegadores na Web, onde é possível encontrar diversos arquivos, tanto imagens mais pessoais (fotos familiares, reuniões de amigos) como imagens que retratam paisagens, objetos; tudo ao sabor da preferência dos navegadores do sistema. No início de sua criação, o Flickr comportava apenas um grupo de sujeitos internautas que ansiavam o compartilhamento de registros pessoais notadamente particulares a uma determinada realidade; no entanto, como na rede a navegação permite constantes deslocamentos, sustentamos que hoje o Flickr inscreve-se como lugar discursivo de pesquisa, consulta e visitação pública de documentos que não estão circunscritos somente à esfera pessoal, já que constam no sistema álbuns tidos como oficiais de políticos, governos, ONGs, institutos, universidade entre outros.

Os arquivos inseridos no sistema são classificados por tags criadas pelos próprios navegadores por meio do processo da folksonomia. A organização das fotos dentro do Flickr começa a partir do momento em que 0 sujeito-navegador insere sua foto no sistema e a nomeia, podendo inserir tags, palavras-chave, para indexar de forma livre o conteúdo da foto. Destacamos aqui a importância da palavra, essa matéria que sempre devemos ao Outro (sobre isso, falamos no nosso remetimento a Pêcheux e Authier-Revuz) para a entrada nesse ponto do Arquivo (ROMÃ0; BENEDETTI, 2008), constituído por diversas imagens, inseridas por tantos outros sujeitos. Para a composição do corpus deste artigo realizamos uma busca pela tag "Brasil" no dia 22 de setembro de 2009, através do critério Interessante. A busca surtiu em 1.433.302 itens. Diante desse volume imenso, resolvemos entrar no menu "Explorar" e inserimos a tag "Brasil" para que o sistema pudesse gerar uma nuvem de tag, mostrando quais tags foram relacionadas juntamente com a tag "Brasil".

Encontramos os seguintes resultados: "brazil", "beach", "rio", "sol", "sunset”, "sky", "azul”, "riodejaneiro", "praia" e "blue". Entendemos essas tags como marcas linguísticas que nos remetem à formação discursiva dominante sobre 
Figura 1: Flickr: explorando a tag "Brasil”. http://www.flickr.com/photos/tags/brasil/interesting/

\section{Explorar / Tags / brasil}

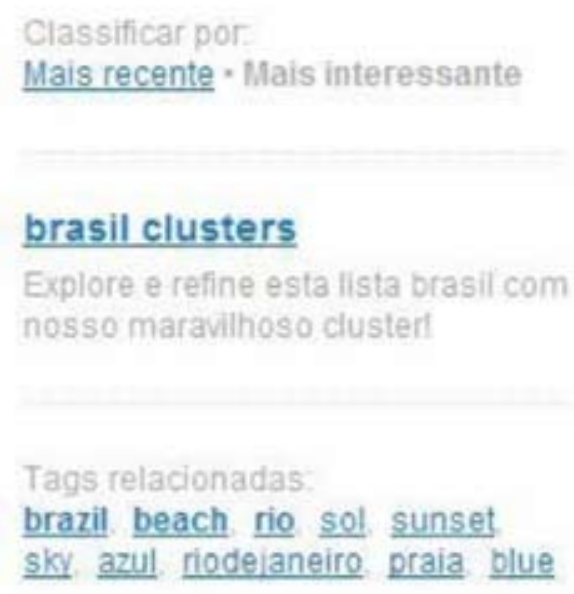

os efeitos de "Brasil", quais sejam, um país composto por praias, sob um céu azul e ao final da tarde com a vista para um pôr-do-sol, sentidos que filiam-se também ao dizer recorrente que situa o Rio de Janeiro como cidade maravilhosa. Esses significantes marcam a instauração de trajetos discursivos que evidenciam uma construção identitária sobre "Brasil" como lugar de exuberâncias naturais, sentido este sustentado pela memória discursiva que vem desde a chegada dos portugueses ao país e repetido exaustivamente até hoje.

A visão paradisíaca da terra começou com os primeiros europeus que nela puseram o pé. Ela está presente já na carta de Caminha. Logo depois, em 1503, Américo Vespúcio, na carta que ficou conhecida como Mundus novus, dirigida a Francesco de Medici, declara que, a existir 0 paraíso terreal, não estaria longe das terras que viu (CARVALH0, 1998, p. 1).

De um lado, esse efeito de riqueza natural paradisíaca, com terra, flora, fauna, hidrografia e clima exuberantes, toma corpo como o primeiro sentido a ser mantido, repetido e ordenado como literal e repetível; ao mesmo tempo, essa nuvem de $\operatorname{tag}$ produz o silenciamento de tantos outros sentidos sobre "Brasil" que poderiam materializar-se e serem encontrados no sistema, mas que foram calados. As tags da nuvem acima não pertencem somente ao conjunto de tags do significante "Brasil", o sujeito ao clicar na tag "sunset" pode vir a recuperar uma imagem 
sobre o pôr-do-sol em uma cidade denominada

Americana, pois uma nuvem de tag inscreve diversos tantos outros sentidos quanto forem possíveis acessar, direcionando o sujeito a diversas outras páginas que se situam antes e depois da página aberta.

Começamos a navegar pelo sistema a partir da pesquisa realizada, à procura das figuras que os navegadores indexaram com a tag "Brasil". Em meio a tantas fotografias, selecionamos quatro figuras para compor nosso corpus de análise, pois consideramos que elas configuram-se como "mais recorrente na busca", tais como a presença constante de fotografias sobre exuberâncias naturais: paisagens praieiras, a bandeira brasileira, flora e a fauna brasileira, a presença recorrente da cidade do Rio de Janeiro e, para instaurar o confronto de sentidos, apontamos como tantos outros arquivos foram silenciados, tanto pela nuvem de $t a g$, quanto pela própria busca. Para marcar esses efeitos de contradição, acrescentamos uma única fotografia que escapa aos sentidos dominantes e que iconiza algo que escapole e desliza dos efeitos de sol, céu e mar, tão cirandados na ordem do repetível.

Ao analisarmos essa imagem acima, vemos que ela pertence à formação discursiva dominante à qual a tag "Brasil" filia-se: um cenário praieiro, marcado pelo sujeito-navegador com as tags, "beach", "praia" e "playa". 0 sujeito tenta realizar um cerceamento dos sentidos

Figura 2: Praia do Forte - BA- Brasil, por Simone Castro. .http://www.flickr.com/photos/simonedecastro/3445577337/

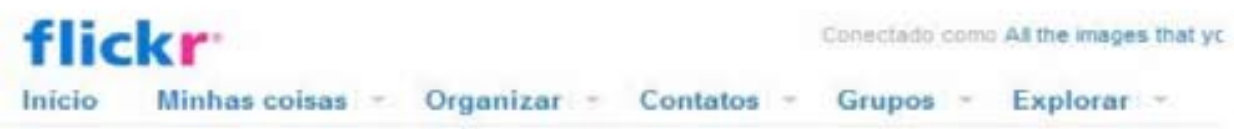

Praia do Forte - Bahia - Brasil

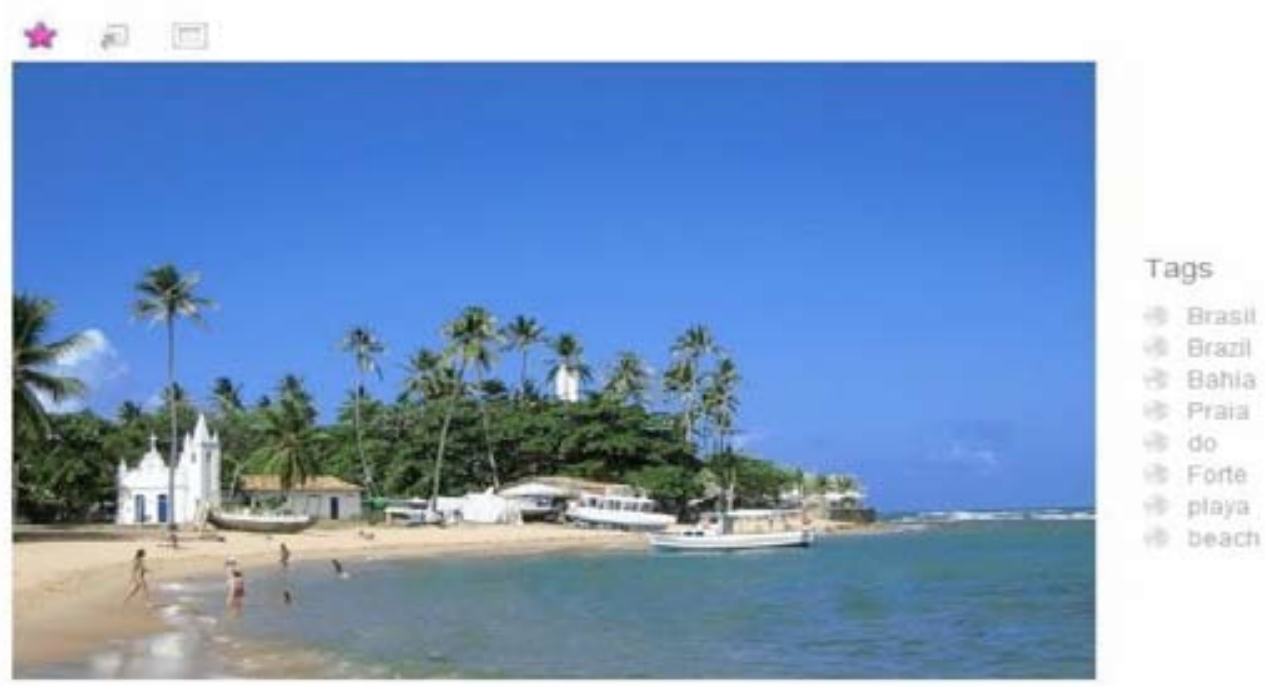


da fotografia em questão, materializando tags que demarcam o local geográfico "Brasil", "Bahia", "Praia do forte", porém, ao fazê-lo, ele silencia alguns outros sentidos da FD dominante, tais como as tags "sky" (céu) e "azul". A presença de tags com idiomas diferentes é algo recorrente no sistema do Flickr e, para nós como analistas do discurso, essa é uma marca indiciária da heterogeneidade da qual já falamos anteriormente. Muitos dos navegadores do sistema, mesmo não sendo provenientes de países de língua inglesa, utilizam-na por ela ser considerada uma "língua universal" na Web; outros porque são mesmo de origem inglesa, 0 que marca as várias vozes que se imbricam na rede, misturando-se. Inicialmente 0 sistema usou o idioma inglês e mais tarde a página foi traduzida para oito idiomas, mesmo assim, muitos optam por indexar seus arquivos com seu idioma e também com a língua inglesa. Além do idioma inglês, o sujeito-navegador utilizou-se também do idioma espanhol. Assim, foi possível observar "beach", "praia" e "playa", "brazil" e "brasil". Ao mobilizar dois ou mais idiomas para indexar seus arquivos, o sujeito antecipa que será mais fácil a recuperação dos mesmos por outros navegadores do sistema provenientes de vários outros lugares do mundo; 0 que configura 0 efeito da folksonomia como produção coletiva, orientada pelo e para o compartilhamento de dados entre internautas. Também anotamos que isso inscreve sócio-historicamente 0 efeito de globalização, de mundo sem fronteiras, de banimento das distâncias, efeitos de sentidos tão largamente repetidos em relação a tecnologias de informação na contemporaneidade.

Neste próximo recorte, temos também uma imagem em um contexto praieiro: marcado pela FD dominante do significante de nossa busca pela tag "Brasil", o sujeito-navegador utilizou também de tags em inglês e português, visando à recuperação das informações no ambiente coletivo.

Porém as tags "saudade", "férias" e "que saudades das minhas férias" configuram-se por "affective tags", nas quais se refere a algo muito particular do sujeito, ou seja, um dado que faz retornar sentidos aos quais apenas ele tem acesso, pois não sabemos de que exatamente ele sente saudade naquela praia; apenas o sujeito que postou a foto pode apontar os elementos de sua saudade. No entanto, ao marcar "saudade", o sujeito mobiliza uma região da memória discursiva que nos permite inferir que estar naquela praia foi algo bom; isso porque "a memória é, então, o que nos torna múltiplos, próximos, mas também o que nos afasta, nos torna únicos, singulares" (FERREIRA, 2008, p. 13). Dessa maneira, o sujeito-navegador - tanto no ato de tirar a fotografia, quanto ao criar as tags sobre o que a imagem lhe invocaevidencia, pelo acesso à memória discursiva, as condições de produção da foto, a historicidade dos sentidos, em meio ao cenário praieiro, típico das férias de muitos brasileiros, a posição dos pés entrecruzados e verticalizados, enquanto 
Figura 3: Praia de Ponta Negra - RN - Brasil, por Dalvinha. http://www.flickr.com/photos/dalvinha/303548972/

\section{flickr}

Inicio Minhas coisas * Organizar * Contatos * Grupos * Explorar

\section{I miss last vacation so badly!}

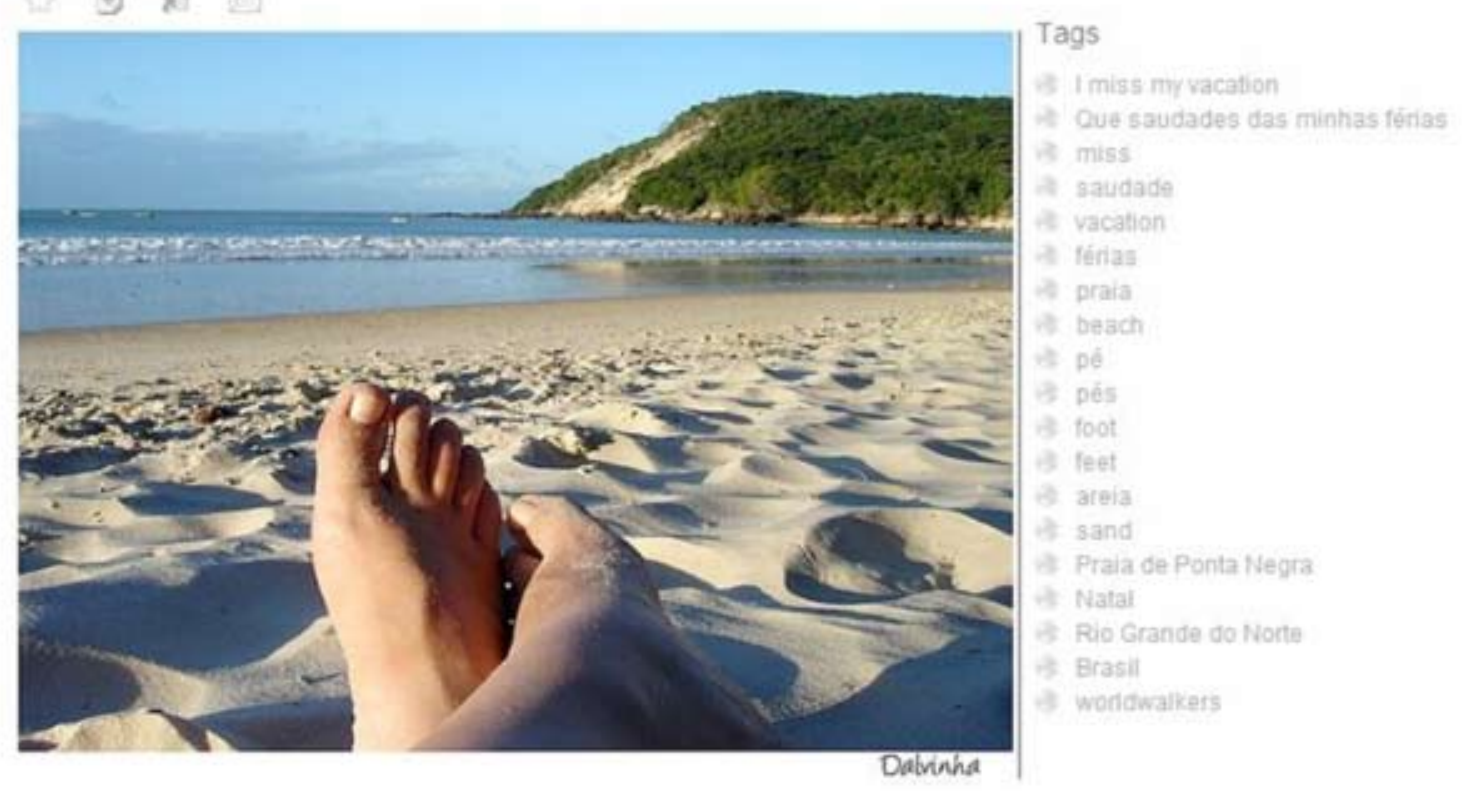

o corpo descansa em meio às areias da praia, da natureza, sentado ou deitado na areia, de e 0 olhar do sujeito apreciando a paisagem, preferência de férias.

marcando a exterioridade dos fatos através da inscrição da história na língua. "Essa presença da exterioridade, como o sentido lá, é o que torna possível a relação do sujeito com a própria língua, relação essa afetada pelas determinações histórico-sociais que se marcam na materialidade do discurso" (FERREIRA, 2008, p. 16). É ainda o acesso à memória discursiva que nos faz significar os pés cruzados na areia como um momento de relaxamento e de não trabalho, ou seja, essa imagem marca a pausa para poder olhar o mar, estando parado e em posição de apreciador

0 sujeito ocupa a posição de que está "com saudade de suas férias" e insere uma tag com o dizer "que saudades das minhas férias", esquecendo-se de outros sentidos que ele poderia atribuir à foto, crendo haver somente uma forma de enunciar, a da posição que ele ocupa, configurandose pelo esquecimento número dois, o enunciativo. Em um sistema de informação, através da taxonomia, não seria possível indexar o documento através dessa tag, pois o desenvolvimento da referida tag foi baseado em interesse especifico do sujeito, algo da singularidade de uma 
situação específica, não havendo um controle do vocabulário. Isso instala as possibilidades de criação no processo de folksonomia direcionada ao e para o navegador do sistema, no qual só o sujeito que a criou pode olhar aquela fotografia e sentir saudades de suas férias, naquela determinada situação e local. Assim, a recuperação dessa fotografia por outros navegadores no sistema pela referida tag não seria possível.

A imagem acima ilustra um dos cartões postais mais clássicos do Brasil, qual seja, a vista para 0
Pão de Açúcar, na cidade do Rio de Janeiro. Pelo discurso dominante, esta imagem é tomada como uma das novas sete maravilhas do mundo, o que se combina com 0 efeito de cidade maravilhosa, também muito repetido. Na ordem do repetível, temos o funcionamento ideológico de efeitos de exuberância, beleza, plasticidade de uma cidade onde mar, céu, mata, clima, enfim, dados naturais promoveriam a representação de "Brasil", país para o qual também é possível recuperar, como já vimos anteriormente, esses mesmos efeitos. Esse sentido dominante, dado sócio-historicamente,

Figura 4: Rio de Janeiro, por JC Couto. http://www.flickr.com/photos/jccouto/406382820/

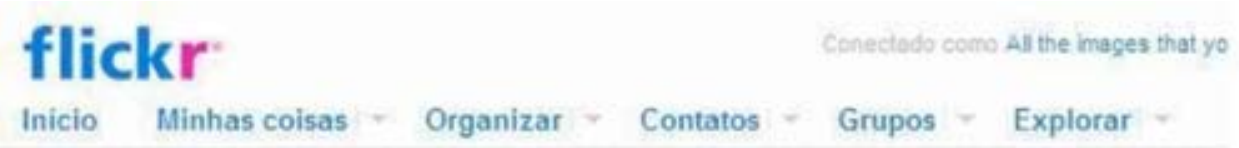

\section{Parabéns !!!}
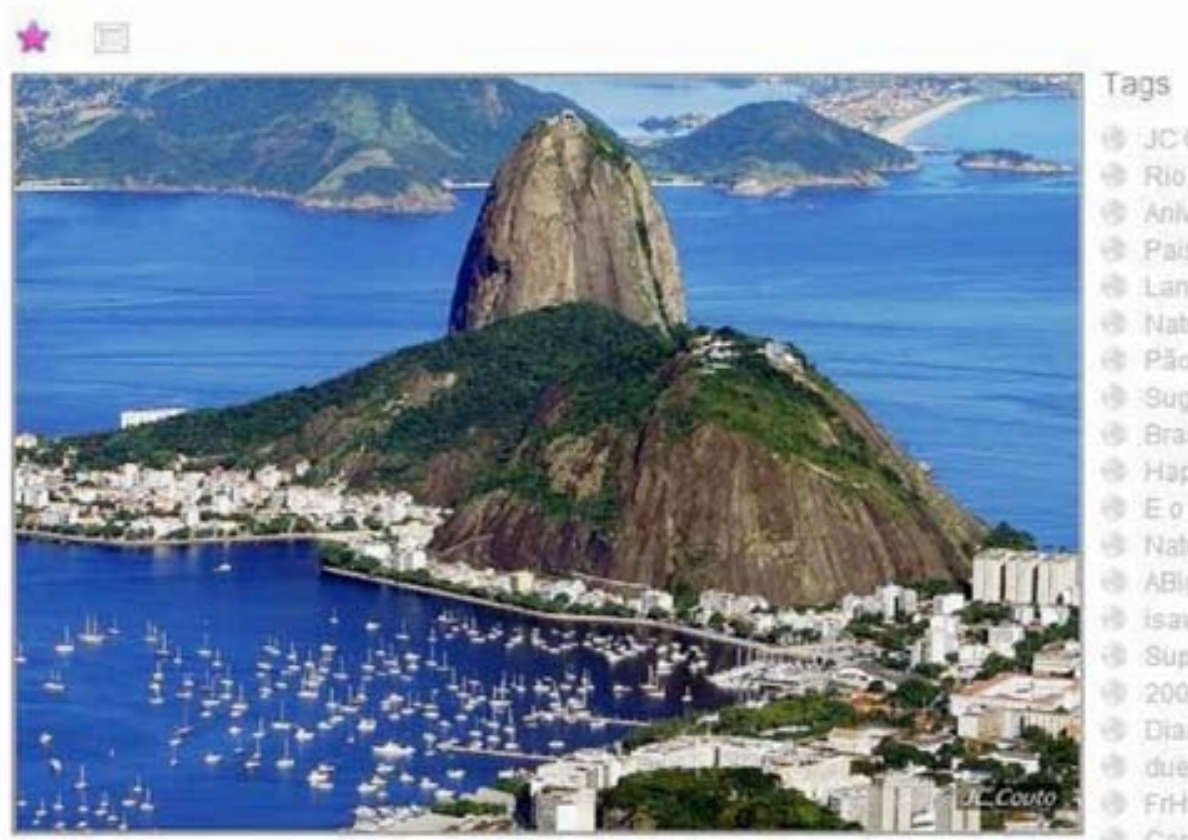
remete-nos a um fio da memória discursiva, no qual está dito que a cidade do Rio de Janeiro foi a capital do país até a construção de Brasília, "e nessa tessitura vai comparecer a memória, operando na montagem dos múltiplos fios, nossos e alheios; fios remendados, cheios de nós, por vezes, rompidos, por vezes saturados" (FERREIRA, 2008, p. 13), fios estes que vão tecendo sentidos sobre "Brasil".

\begin{abstract}
A matriz metonímica geográfico-cultural da identidade brasileira é o Rio de Janeiro (veja também Achúgar e Bustamante op. cit.). Dada a importância da mídia na formação da comunidade imaginada nacional e na difusão de imagens internamente ao sistema mundial, não é de estranhar que, em conjunção com os processos históricos centralizadores e homogeneizadores típicos de quando exercia a função de capital federal, o Rio de Janeiro, com a sua importância no domínio de meios de comunicação de alcance nacional (sobretudo da televisão), tenha sido a fonte de representações que predominam sobre o Brasil”. (RIBEIR0, 1998, p. 9).
\end{abstract}

O sujeito-navegador, ao construir a tags para indexar a imagem, realizou o processo da folksonomia orientada pelo que ele antecipa como sendo a comunidade ou o coletivo, porém, com um viés para os navegadores que buscam a fotografia em seu aspecto mais técnico e artístico, tais como a presença de tags que abordam a marca da câmera fotográfica, nome do fotógrafo, entre outros aspectos fotográficos. Esses traços são, na maioria, compreendidos por outros sujeitos-navegadores que compartilham da mesma memória discursiva sobre a técnica na/da fotografia. Através do enunciado " $E$ o Rio continua lindo" materializado em forma de tag, foi possível observar a heterogeneidade de forma constitutiva, a qual é sustentada pela memória, ou pelo interdiscurso de uma música já muito cantada em nome do Rio e para ele. Assim, 0 navegador que teve 0 acesso ao interdiscurso sobre a música "Aquele abraço", de autoria de Gilberto Gil, conseguiu perceber que a tag em questão não está isenta de um já-dito, pois ela configura-se, move-se, constitui-se a partir dele. Na discussão teórica, marcamos 0 quanto a noção de já-lá é importante para os estudos discursivos, visto que as palavras já foram ditas antes e em outro lugar, permitindo ao sujeito bordá-las, tomá-las de empréstimo de outros sujeitos em uma espiral sem fim, como no trecho da música de Gil, "O Rio de Janeiro continua lindo...". Marcamos, ainda, que a heterogeneidade diz respeito à presença do Outro como parte constitutiva do sujeito e da linguagem, mostrando que não há um discurso homogêneo, isento de outros dizeres, instituído por um sujeito uno que seja a origem e fonte dos sentidos e dos dizeres. No caso da fotografia e da tag que selecionamos, 0 efeito de repetição da continuidade da beleza carioca retorna como a dizer que, mesmo depois de tanto tempo e mesmo em meio a tantas contradições sociais, o Rio continua a ser uma linda terra, a ter sua beleza assegurada.

No enunciado "Parabéns", o sujeito-navegador instaura diversos outros sentidos que dialogam com a imagem, tais como sentidos de parabenizar a cidade pela beleza da sua paisagem como a 
instalar mais um elogio à "Cidade Maravilhosa"; porém, ao criar as tags, o sujeito-navegador condensa os sentidos de beleza da imagem, parabenizando a cidade do Rio de Janeiro pelo seu aniversário e instalando as tags "Aniversário", "Happy birthday Rio". Isso nos permite inferir que 0 sujeito, através da linguagem, sempre marca algumas palavras, esquecendo que outras poderiam estar ali a ocupar o lugar das primeiras. Assim, sempre haverá diferentes formas de significar os objetos, porém, como na folksonomia não há uma metodologia específica, o sujeito indexa, nomeia e organiza seus arquivos mobilizando regiões da memória discursiva às quais teve acesso; assim ele pode significar as tags que, pelo efeito ideológico de evidência, parecem inscrever sentidos naturais, óbvios e transparentes ao sujeito na posição em que ele está. Desta forma, o sujeito, ao utilizar o processo da folksonomia para confeccionar as tags, não tenta controlar todos os sentidos possíveis nem normatizar 0 seu vocabulário, tampouco tem a pretensão de trabalhar com processos regrados. Os deslizes e rupturas dos sentidos tidos como dominantes estão sempre mais aparentes na folksonomia, como foi possível visualizarmos até agora, mesmo dentro das nuvens de $\mathrm{tag}$.

Como observamos na nuvem de tag e através da busca realizada no Flickr sobre os sentidos instalados na tag "Brasil", há um sentido dominante cristalizado, no qual silenciam outros diversos sentidos sobre "Brasil" a partir das tags que indexam as figuras. Pouquíssimas imagens sobre favela, pobreza e violência puderam ser vistas e encontradas nesse sistema com a indexação da tag "Brasil", o que, para nós como analistas do discurso, é um dado bastante importante, visto que podemos concluir que a discussão em torno do(s) conflito(s) da trama narrativa-Brasil ficou capenga e reduzida a belezas naturais, à bandeira, ao povo ou às cidades brasileiras, deixando em evidência a formação discursiva dominante sobre os sentidos de um verdadeiro "paraíso tropical".

Um dos raros recortes que encontrados a problematizar historicamente outros sentidos de "Brasil" é o que se segue. Nós o selecionamos justamente para marcar os sentidos que foram esquecidos pelos sujeitos-navegadores e que não puderam ser ditos ou materializados na língua pela maioria dos registros. Segundo Orlandi (2003, p. 36), "os sujeitos 'esquecem' o que já foi dito - e este não é um esquecimento voluntário - para, ao se identificarem com o que dizem, se constituírem em sujeitos"; de acordo com esse postulado, marcamos que a fotografia e as tags que seguem abaixo configuram-se como um discurso no qual o esquecimento produz um sentido marcado na/pela língua e na história.

0 sujeito-navegador captura a imagem de um morador de rua deitado sobre o chão de uma capital brasileira com os pés destacados no plano central, com detalhes de bolhas. Os pés evocam sentidos marcados pelo cansaço, sofrimento, 
posto que estão calejados, repletos de acúmulos de fluídos entre as camadas interna e externa da pele, devido ao excesso de fricção e a queimaduras ocasionadas pelo frio, calor ou muito sol. Enquanto na figura 2 temos uma filiação à formação discursiva dominante com os pés do sujeito em férias descansando sobre as areias da praia sob 0 céu azul, o que o sujeito-navegador nomeia como a saudade de suas férias; aqui temos os pés também deitados, mas na via pública, tomados pelo cansaço e promotores da condição de marginalidade.

Nessas duas fotos, poderíamos encontrar a contradição social que marca uma das feições mais violentas do nosso país, ou seja, o confronto de sentidos de in e exclusão. Porém, nas tags encontradas, isso não foi dito, pois as etiquetas sobre a figura do morador de rua marcam detalhes sobre a potência técnica da máquina fotográfica, a capacidade de focar e captar detalhes distantes do fotógrafo, a localização geográfica, inscrevendo como objeto central a arte da fotografia, e deixando como adereço o morador de rua e seus pés cansados e tombados.

Temos, então, um duplo silenciamento: primeiro porque são poucas as imagens que incluem

Figura 5: Morador de rua, por Francisco Aragão. http://www.flickr.com/photos/aragao/2173408387/

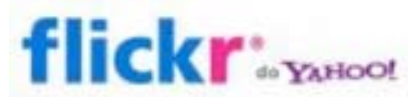

Inicio Minhas coisas - Organizar * Contatos * Grupos * Explorar *

\section{Homeless (Details) - Brasília - Brasil}

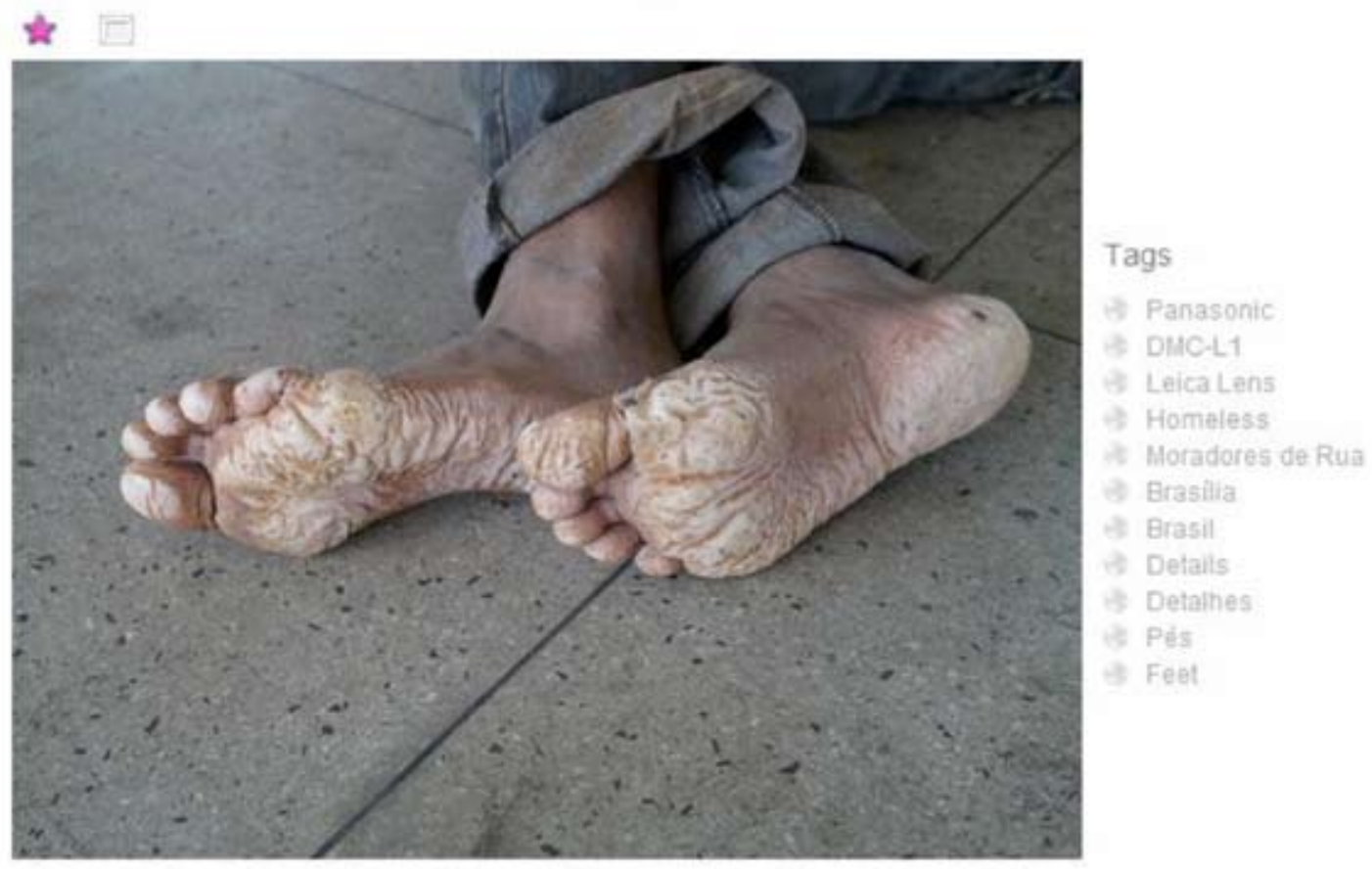


cenas de exclusão social, abandono, violência; segundo porque, quando o sujeito-navegador iconiza esses efeitos de sentido, o faz deixando de dizer sobre eles, apagando seus efeitos tidos como indesejáveis e promovendo-os apenas como moldura, detalhe, adereço para produzir outro(s) sentido(s). A existência de fotos como essas, nos resultados principais das fotos disponibilizadas no Flickr, não são muitas. Quando são encontradas, observamos que as mesmas são tiradas e expostas em sua maioria por sujeitosnavegadores que apreciam, enunciam e produzem sentidos a respeito da fotografia técnica e artística. Dificilmente alguém tira fotografias e as faz circular sobre coisas que, pelo efeito ideológico de evidência, são consideradas como não agradáveis e não belas. Por isso, podemos notar 0 apagamento de sentidos que fogem à formação discursiva dominante, sobre 0 que é belo, sobre o que é merecedor de estar na rede e sobre que deve circular, em foto e verbo, sobre o "Brasil". Completamos que o dizer do sujeito sobre si mesmo é algo recorrente no sistema; assim, temos a posição do sujeito que introduz suas fotos deixando suas marcas discursivas a partir de sua posição ao sabor do que a ideologia lhe permite dizer e do que a memória lhe permite filiar-se. Por isso, dificilmente encontramos fotografias e palavras dissonantes da formação discursiva dominante, principalmente as tags, pois o sujeito-navegador não se coloca na posição do sujeito discursivizado na imagem tal como a posição do morador de rua. Já na imagem dos pés do sujeito-navegador na praia, observamos outro movimento de sentidos, qual seja o sujeito discursivizando sobre si mesmo e criando tags que só são possíveis porque ele se coloca como seu próprio objeto.

\section{Parada (sempre) inconclusa: a rede e seus desdobramentos}

0 real não está na saída nem na chegada:
ele se dispõe para a gente
é no meio da travessia.
Guimarães Rosa

Através da folksonomia, é possível notar os movimentos do sujeito-navegador na rede eletrônica, pois, segundo Castells (2001, p. 255), a Internet "é um meio de comunicação, de interação e de organização social"; e a folksonomia tem mostrado o modo como 0 sujeito-navegador organiza seus dados na rede e também estabelece uma (relativa) ordem, contorno e borda na rede, que se apresenta fluída o suficiente para promover a imersão, a navegação e a dispersão de dados. Dessa maneira, estamos diante de marcas linguísticas e ideológicas que, no funcionamento discursivo, instalam sentidos que o sujeito atribui aos (seus) dizeres que circulam na malha digital. Observamos ainda que a polissemia que recuperamos pela busca da tag "Brasil", da qual derivaram os recortes utilizados neste trabalho, seria silenciada em todos os arquivos dos sistemas utilizados neste trabalho, Flickr, em prol de uma identificação de conceitos, 
privilegiando um sentido em detrimento de outros que rompem com o já estabelecido: "a polissemia coloca o 'mesmo' e aponta para a ruptura, para a criatividade: presença da relação homem-mundo, intromissão da prática $\mathrm{na} /$ da linguagem, conflito entre o produto, 0 institucionalizado, e o que tem de se instituir" (ORLANDI, 2003, p. 137). Na perspectiva discursiva, não percorremos a procura de um sentido literal de "Brasil"; se o que há é um sentido dominante dado sócio-historicamente como literalidade do efeito ideológico, acreditamos que a folksonomia, bem como a busca por tags no Flickr, apontam a heterogeneidade na materialidade verbal e os movimentos dos sujeitos e dos sentidos nos arquivos e na língua.

\section{Referências bibliográficas}

AQUINO, Maria Clara. Hipertexto 2.0, folksonomia e memória coletiva: um estudo das tags na web. E-Compós, Brasília, v. 9, p. 1-15, 2007.

AUTHIER-REVUZ, Jacqueline. Heterogeneidade mostrada e heterogeneidade constitutiva: elementos para uma abordagem do outro no discurso. In:

. Entre a transparência e a opacidade: um estudo enunciativo do sentido. Porto Alegre: EDIPUCRS, 2004.

BRANSKI, Regina. Recuperação de informações na Web. Perspectivas em Ciências da Informação, Belo Horizonte, v. 9, n. 1, p. 70-87, jan./jun. 2004.

CARVALHO, José Murilo. 0 motivo edênico no imaginário social brasileiro. Revista brasileira de

Ciência e Sociedade, São Paulo, v. 13 n. 38, out. 1998. Disponível em: <http://www.scielo.br/scielo. php?pid=S010269091998000300004\&script=sc i_abstract\&tlng=en>. Acesso em: 25 sey. 2009.
CASTELLS, Manuel. A sociedade em rede: a era da informação: economia, sociedade e cultura. São Paulo: Paz e Terra, 2001.

CATARINO, Maria Elisabete, BAPTISTA, Ana Alice. Folksonomia: um novo conceito para a organização dos recursos digitais na Web. DatagramaZero -

Revista de Ciência da Informação, Rio de Janeiro, v. 8 n. 3 jun/07 .Disponível em: <http://www.dgz.org.br/ jun07/Art_04.htm>. Acesso em: 8 jun. 2008.

CHARTIER, Roger. Os desafios da escrita. São Paulo: UNESP, 2002.

FERREIRA, Maria Cristina. A ciranda dos sentidos. In: ROMÃ0, Lucilia Sousa; GASPAR, Nádea Regina (orgs.). Discurso midiático: sentidos de memória e arquivo. São Carlos: Pedro \& João, 2008.

FLICKR. Disponível em: <http://www.flickr.com/>. Acesso em: 4 out. 2009.

FOUCAULT, Michel. A arqueologia do saber. Petrópolis: Vozes, 1969.

A ordem do discurso. São Paulo: Loyola, 2005.

HSIEH, Wen-Tai.; YEN-LIN, Chen.; SENG-CHO, Chou. A collaborative desktop tagging system for group knowledge management based on concept space.

Expert Systems with Applications, Adelphi, v. 36, n. 5, p. 9513-9523, 2009.

KIPP, Margaret. @toread and cool: tagging for time, task and emotion. In: information architecture summit, 8., Las Vegas, 2007. Proceedings... Las Vegas: ASIST, 2007.

LIPCZAK, Marek. Tag recommendation for folksonomies oriented towards individual users. In: European conference on machine learning and principles and practice of knowledge discovery in databases, 8. , 2008, Antwerp .Proceedings... Antwerp: ECML PKDD Discovery Challenge, 2008. Disponível em: <www.kde.cs.uni-kassel.de/ws/rsdc08/ pdf/10.pdf> . Acesso em: 23 maio 2009. 
MAINGUENEAU, Dominique. Novas tendências em análise do discurso. Campinas: Pontes, 1993.

\section{MARCUSCHI, L. A.; XAVIER, A. C. S. Hipertexto e} gêneros digitais: novas formas de construção de sentido. Rio de Janeiro: Lucerna, 2005.

MOREIRA, Vivian Lemes; ROMÃo, Lucília Sousa. 0 funcionamento discursivo das nuvens de tags na rede eletrônica: sentidos sobre Capitolina. Datagramazero, Rio de Janeiro, v. 10, 2009.

MOREIRA, Vivian Lemes; SILVA, Jonathan Bertassi. ; ROMÃO, Lucília Sousa. Heterogeneidade inscrita no discurso do website Flickr. Hipertextus, Recife, v. 4, p. $1-19,2010$.

NARVAZ, Martha; NARDI, Henrique; MORALES, Blanca. Nas tramas do discurso: a abordagem discursiva de Michel Pêcheux e de Michel Foucault. Revista de Psicologia Política, Belo Horizonte, v. 6, n. 12, 2006. ORLANDI, Eni. As formas de silêncio: no movimento dos sentidos. Campinas: Unicamp, 1997.

A linguagem e seu funcionamento: as formas do discurso. 4. ed. Campinas: Pontes, 2003.

PÊCHEUX, Michel. Papel da memória. Campinas: Pontes, 1999.

. A análise automática do discurso. In: GADET, F.; HAK, T. (orgs.). Por uma análise automática do discurso: uma introdução à obra de Michel Pêcheux. Campinas. Unicamp. 1983. p. 61-105.

o discurso: estrutura ou acontecimento.

Campinas: Pontes, 1990.

RIBEIRO, Gustavo. 0 que faz o Brasil, Brazil: jogos

identitários em San Francisco. Brasília: Departamento de Antropologia da Universidade de Brasília, 1998.

(Série Antropologia).

ROMÃ0, Lucília Sousa; BENEDETTI, Claúdia. A navegação do sujeito no discurso jornalístico impresso e eletrônico. Verso e Reverso, América do Norte, v. 22, 2008. Disponível em: http://www.revistas.

univerciencia.org/index.php/versoereverso/article/ view/5757. Acesso em: 3 jul. 2008.

WURMAN, Richard. Ansiedade de informação: como transformar informação em compreensão. São Paulo: Cultura, 1991. 


\section{Discourse and folkosonomy:} Brazil dressed with some tags

\section{Abstract}

The aim of this research is to discuss the organization method and the digital files index done by the subject-narrator on the Web. Thus, it is established a delineation and discussion about the discourse introduced by the subject on the Internet, considering the production conditions of electronic discourse. Mobilizing the concepts about Internet and folksonomy, we intend to construct a dialogue with French Discourse Analysis to investigate the discursive functioning of tags, words used for indexing files on the Web in a rather free way. This way we can observe the way the tag "Brazil" has been used by subjects to nominate and index the files on Flickr website. For this purpose, we will analyze the linguistic marks left by the subjects on tags, those that make it say (and be silent about) certain words, investigating the way sayings are installed through the folksonomy process.

\section{Keywords}

Discourse. Subject. Folksonomy. Brazil. Internet.

\section{Discurso y folksonomía: Brasil vestido con algunas etiquetas}

\section{Resumen}

Este trabajo tiene como objetivo discutir las formas de organización y indexación de los archivos digitales utilizados por el sujeto-navegante en el ambiente electrónico. Así, se estableció un diseño y un análisis acerca del discurso introducido por el sujeto en Internet, teniendo en cuenta las condiciones de producción del lenguaje electrónico. Movilizando los conceptos de Internet y folksonomía, queremos construir un diálogo con el Análisis del Discurso de filiación francesa con la finalidad de investigar el funcionamiento discursivo de las etiquetas; palabras que hacen la indexación de forma considerada libre a los archivos en Internet. Así, observaremos cómo la etiqueta "Brasil" ha sido utilizada por los sujetos para nombrar e indexar los archivos del sitio Flickr. Para este curso se analizarán las marcas lingüísticas dejadas por los sujetos en las etiquetas, estas que hacen hablar (y silenciar) ciertas palabras, observando cómo las palabras se instalan a través del proceso de folksonomía.

\section{Palabras clave}

Discurso. Sujeto. Folksonomía. Brasil. Internet. 


\section{Expediente}

A revista E-Compós é a publicação científica em formato eletrônico da Associação Nacional dos Programas de Pós-Graduação em Comunicação (Compós). Lançada em 2004, tem como principal finalidade difundir a produção acadêmica de pesquisadores da área de Comunicação, inseridos em instituições do Brasil e do exterior.

\section{E-COMPÓS I www.e-compos.org.br I E-ISSN 1808-2599}

Revista da Associação Nacional dos Programas de Pós-Graduação em Comunicação. Brasília, v.13, n.1, jan./abr. 2010.

A identificação das edições, a partir de 2008, passa a ser volume anual com três números.

\section{CONSELHO EDITORIAL}

Afonso Albuquerque

Universidade Federal Fluminense, Brasil

Alberto Carlos Augusto Klein

Universidade Estadual de Londrina, Brasil

Alex Fernando Teixeira Primo

Universidade Federal do Rio Grande do Sul, Brasil

Alfredo Vizeu

Universidade Federal de Pernambuco, Brasil

Ana Carolina Damboriarena Escosteguy

Pontifícia Universidade Católica do Rio Grande do Sul, Brasil

Ana Silvia Lopes Davi Médola

Universidade Estadual Paulista, Brasil

André Luiz Martins Lemos

Universidade Federal da Bahia, Brasil

Ângela Freire Prysthon

Universidade Federal de Pernambuco, Brasil

Antônio Fausto Neto

Universidade do Vale do Rio dos Sinos, Brasil

Antonio Carlos Hohlfeldt

Pontifícia Universidade Católica do Rio Grande do Sul, Brasil

Arlindo Ribeiro Machado

Universidade de São Paulo, Brasil

César Geraldo Guimarães

Universidade Federal de Minas Gerais, Brasil

Cristiane Freitas Gutfreind

Pontifícia Universidade Católica do Rio Grande do Sul, Brasil

Denilson Lopes

Universidade Federal do Rio de Janeiro, Brasil

Eduardo Peñuela Cañizal

Universidade Paulista, Brasil

Erick Felinto de Oliveira

Universidade do Estado do Rio de Janeiro, Brasil

Francisco Menezes Martins

Universidade Tuiuti do Paraná, Brasil

Gelson Santana

Universidade Anhembi/Morumbi, Brasil

Goiamérico Felício

Universidade Federal de Goiás, Brasil

Hector Ospina

Universidad de Manizales, Colômbia

Herom Vargas

Universidade Municipal de São Caetano do Sul, Brasil

leda Tucherman

Universidade Federal do Rio de Janeiro, Brasil

Itania Maria Mota Gomes

Universidade Federal da Bahia, Brasil

Janice Caiafa

Universidade Federal do Rio de Janeiro, Brasil

Jeder Silveira Janotti Junior

Universidade Federal da Bahia, Brasil
João Freire Filho

Universidade Federal do Rio de Janeiro, Brasil

John DH Downing

University of Texas at Austin, Estados Unidos

José Luiz Aidar Prado

Pontifícia Universidade Católica de São Paulo, Brasil

José Luiz Warren Jardim Gomes Braga

Universidade do Vale do Rio dos Sinos, Brasil

Juremir Machado da Silva

Pontifícia Universidade Católica do Rio Grande do Sul, Brasil

Lorraine Leu

University of Bristol, Grã-Bretanha

Luiz Claudio Martino

Universidade de Brasília, Brasil

Maria Immacolata Vassallo de Lopes

Universidade de São Paulo, Brasil

Maria Lucia Santaella

Pontifícia Universidade Católica de São Paulo, Brasil

Mauro Pereira Porto

Tulane University, Estados Unidos

Muniz Sodre de Araujo Cabra

Universidade Federal do Rio de Janeiro, Brasil

Nilda Aparecida Jacks

Universidade Federal do Rio Grande do Sul, Brasil

Paulo Roberto Gibaldi Vaz

Universidade Federal do Rio de Janeiro, Brasil

Renato Cordeiro Gomes

Pontifícia Universidade Católica do Rio de Janeiro, Brasil

Ronaldo George Helal

Universidade do Estado do Rio de Janeiro, Brasil

Rosana de Lima Soares

Universidade de São Paulo, Brasil

Rossana Reguillo

Instituto Tecnológico y de Estudios Superiores do Occidente, México

Rousiley Celi Moreira Maia

Universidade Federal de Minas Gerais, Brasil

Samuel Paiva

Universidade Federal de São Carlos, Brasil

Sebastião Albano

Universidade Federal do Rio Grande do Norte, Brasil

Sebastião Carlos de Morais Squirra

Universidade Metodista de São Paulo, Brasil

Simone Maria Andrade Pereira de Sá

Universidade Federal Fluminense, Brasi

Suzete Venturelli

Universidade de Brasília, Brasil

Valério Cruz Brittos

Universidade do Vale do Rio dos Sinos, Brasil

Veneza Mayora Ronsini

Universidade Federal de Santa Maria, Brasil

Vera Regina Veiga França

Universidade Federal de Minas Gerais, Brasil

\section{COMISSÃO EDITORIAL}

Felipe da Costa Trotta I Universidade Federal de Pernambuco, Brasil Rose Melo Rocha I Escola Superior de Propaganda e Marketing, Brasil CONSULTORES AD HOC

João Maia I Universidade do Estado do Rio de Janeiro, Brasil Sandra Gonçalves I Universidade Federal do Rio Grande do Sul, Brasil Mayra Rodrigues Gomes I Universidade de São Paulo, Brasil Gisela Castro I Escola Superior de Propaganda e Marketing, Brasil João Carrascoza I Escola Superior de Propaganda e Marketing, Brasil Luciana Pellin Mielniczuk I Universidade Federal de Santa Maria, Brasil Irene de Araújo Machado I Universidade de São Paulo, Brasil Hermilio Pereira dos Santos Filho I Pontifícia Universidade Católica, Brasil Benjamim Picado I Universidade Federal Fluminense, Brasil Maria Apaecida Baccega I Escola Superior de Propaganda e Marketing, Brasil Rogério Ferraraz I Universidade Anhembi Morumbi, Brasil

Bruno Souza Leal I Universidade Federal de Minas Gerais, Brasi REVISÃO DE TEXTO E TRADUÇÃo I Everton Cardoso EDITORAÇ̃o ELETRÔNICA I Roka Estúdio
COMPóS I www.compos.org.br

Associação Nacional dos Programas de Pós-Graduação em Comunicação

Presidente

Itania Maria Mota Gomes

Universidade Federal da Bahia, Brasil

itania@ufba.br

Vice-presidente

Julio Pinto

Pontifícia Universidade Católica de Minas Gerais, Brasil juliopinto@pucminas.br

Secretária-Geral

Ana Carolina Escosteguy

Pontifícia Universidade Católica do Rio Grande do Sul, Brasil carolad@pucrs.br 